\title{
Shape Memory and Superelasticity Editorial Board Members Elected 2018 ASM Fellows
}

Shape Memory and Superelasticity is proud to announce that two members of the journal's editorial board, Ibrahim Karaman and Michael Mitchell, have been named to ASM International's 2018 Class of Fellows. ASM established the Fellow of the Society honor in 1969, to provide recognition to members for their distinguished contributions to materials science and engineering and to develop a broad-based forum of technical and professional leaders to serve as advisors to the Society. This year's awards will be presented at ASM's annual Awards Dinner on October 16, 2018 in Columbus, Ohio during MS\&T'18.

Professor Ibrahim Karaman, FASM, Chevron Professor and Head of the Department of Materials Science and Engineering at Texas A\&M University in College Station, Texas is recognized "for contributions to the understanding of structure-property-processing relationships in ferromagnetic shape memory alloys and ultrafinegrained materials, shape memory alloy materials for extreme environment applications and microstructure engineering through severe plastic deformation."

Dr. Michael R. Mitchell, FASM, President, Mechanical \& Materials Consulting, LLC in Flagstaff, Arizona is awarded the honor "in recognition as an international leader in the areas of research, development, and education in the fatigue and fracture behavior of materials for ground vehicles, aerospace systems, and medical devices."

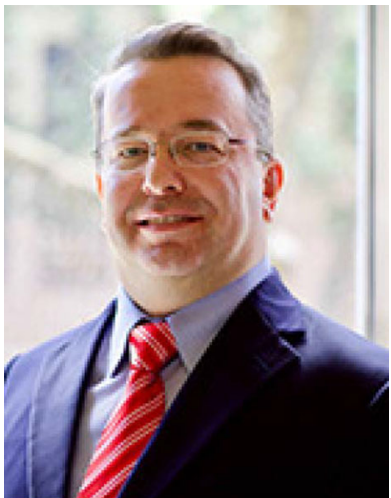

Prof. Ibrahim Karaman

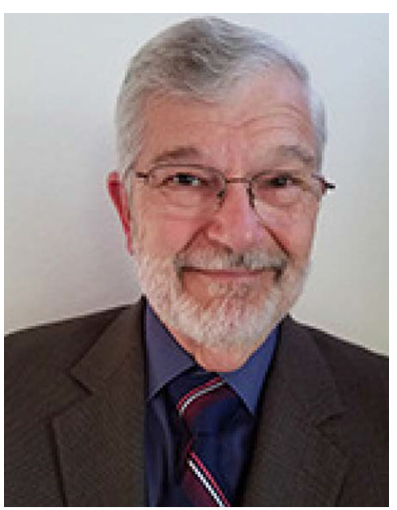

Dr. Michael R. Mitchell 